\title{
Assessment of Agreement between 99mTc-DMSA Renal Scan and Ultrasonography in the Evaluation of Renal Pathology in Children with Recurrent urinary tract infection
}

\author{
Tamanna Jahan, Shamim M F Begum, Rahima Parveen, Md. S Shalekhin \\ National Institute of Nuclear Medicine and Allied Sciences, Dhaka, Bangladesh \\ Correspondence: Dr.TamannaJahan, MBBS, M.Phil (Nuclear Medicine) \\ Former student of National Institute of Nuclear Medicine \& Allied Sciences, \\ Dhaka, Bangladesh, Email: tamanna_mira@yahoo.com.
}

\begin{abstract}
Imaging of urinary tract plays a very important role in children with recurrent urinary tract infection (UTI). Various imaging techniques are used and the imaging protocol in children with UTI continues to be a subject of debate. Most authors recommended combination of imaging. The children with recurrent urine infection may be at increased risk of renal parenchymal scarring, hypertension, impaired renal function and end stage renal disease. But early diagnosis and timely proper treatment has an excellent prognosis. 99m-Tc-dimercaptosuccinic acid (DMSA) renal scan and Ultrasonography (US) are routinely performed studies in children with recurrent UTI. If there is agreement between these two investigation procedures, they will be interchangeable, which will benefit the patient by one procedure instead of two. This will be less time consuming and cost effective.
\end{abstract}

This analytical study was carried out at the National Institute of Nuclear Medicine and Allied Sciences (NINMAS), Bangabandhu Sheikh Mujib Medical University campus, Dhaka, from July 2013 to June 2014, for a period of 12 months. The objective of this study was to assess the agreement between $99 \mathrm{mTc}$ dimercaptosuccinic acid (DMSA) renal scan and Ultrasonography (US) US for evaluating the renal size, renal position, pelvicalyceal dilatation, hydronephrosis and renal scarring in children with recurrent UTI.

Study population consisted of 85 children with age range of 6 months to 12 years, who had laboratory evidence of at least two incidence of UTI within 6 months period. All children underwent 99mTc-DMSA renal scan (plannar) and renal tract ultrasonography (US). Among 85 children, $26(30.6 \%)$ had normal DMSA scan and $59(69.4 \%)$ had abnormal DMSA scan findings. In case of US, 23 (27.1\%) had normal US findings and $62(72.9 \%)$ had abnormal US findings of renal system. The comparison of DMSA renal scan and US findings were done by Kappa analysis to see their agreement in the evaluation of size, position, pelvicalyceal dilatation and hydronephrosis. This study gave an impression that DMSA scan and US has good agreement in the evaluation of renal size, position of the kidney and fair agreement in the evaluation of presence of hydronephrosis. In case of mild pelvicaliceal dilatation evaluation, DMSA was underestimated comparing to US.
The overall accuracy of US for the evaluation of focal scarring of right and left kidney were $89.4 \%$ and $78.8 \%$ respectively. For the evaluation of diffuse scarring the overall accuracy of US were $92.9 \%$ and $97.6 \%$ for the right and left kidney respectively. Therefore, in the evaluation of renal scarring the accuracy of US was underestimated by using DMSA scan as a gold standard.

In the evaluation of kidney size, position and presence of hydronephrosis, both DMSA and US can be interchangeable. Whereas DMSA was underestimated comparing to US in the evaluation of mild pelvicaliceal dilatation. On the other hand DMSA renal scan is more sensitive and specific for detecting cortical scaring compared to the US. In light of present study, both DMSA scan and US are recommended in the combination for complete evaluation of renal abnormalities in recurrent UTI.

Key words: ${ }^{99} \mathrm{~m}$ Tc-DMSA renal scan, Renal abnormalities, Ultrasonography, Recurrent urinary tract infection

\section{INTRODUCTION}

Urinary tract infection (UTI) is a common febrile illness in children and is defined as multiplication of organisms in the urinary tract. It is associated with the presence of neutrophils and more than 100, 000 CFUs (colony forming units) per $\mathrm{ml}$ of midstream urine sample (1). The recurrent UTI can be defined as two or more incidence of UTIs over a six-months period (2). The common risk factors for recurrent UTI include voiding dysfunction, constipation, underlying anatomical abnormality etc (3). Recurrence may occur due to inadequate treatment or bacterial persistence in an unrecognized anatomic site having abnormality (4). Congenital anomalies of kidney and urinary tract occur in approximately $3.3 \%-11.1 \%$ of the population and they account for about $50 \%$ of all congenital abnormalities. Renal anomalies are commonly associated with UTI, stone formation, hydronephrosis and renal failure (5). 
UTI may present with variety of underlying abnormalities like vesicoureteral reflux (VUR), obstructive uropathy, urolithiasis, nephrolithiasis and ureteral duplication (3). The children with recurrent urine infection may be at increased risk of renal parenchymal scarring, hypertension, impaired renal function and end stage renal disease (6). So early diagnosis and adequate treatment of renal abnormalities associated with recurrent UTI is very important. UTI have an excellent prognosis if it is diagnosed timely and treated adequately.

Imaging of urinary tract plays a very important role in the detection of renal abnormalities after first onset of UTI. Various imaging techniques are used and the most common techniques include ultrasonography, voiding cystourethrography, radionuclide renal cortical scintigraphy, radionuclide cryptogram and intravenous urography (7). $99 \mathrm{mTc}$-DMSA renal scan is a well-practiced diagnostic modality at NINMAS and Ultrasonography is routinely performed in children with recurrent UTI to detect renal abnormalities, which are either congenital or acquired.

The imaging protocol in children with UTI continues to be a subject of debate. Optimal diagnostic imaging protocols for identifying the renal abnormalities in recurrent UTI in children needs to be addressed. Most authors recommended combination of DMSA renal scan and US (8). This prospective study was undertaken with the objective to assess the agreement between DMSA scan and USG in the evaluation of children with recurrent UTI. If there is an agreement between two investigation procedures, the patient can be benefited by one procedure instead of two, which will be less time consuming and cost effective for the patient.

\section{MATERIALS AND METHODS}

This is a cross sectional analytical study carried out at the National Institute of Nuclear Medicine and
Allied Sciences (NINMAS), Bangabandhu Sheikh Mujib Medical University, Dhaka campus, from July 2013 to June 2014, for a period of 12 months. A total number of 85 children (27 males and 58 females) with an age range of 6 months to 12 years old, who had history of recurrent UTI and laboratory evidence

of UTI were included. Patients with HTN, DM, SLE or other connective tissue disorder, patients with history of chronic renal failure or any other associated infection were excluded from this study. This study protocol was based on the regulations of the hospital ethical committee. Proper history was taken from all patients attendants according to the data collection sheet. Then every children underwent 99mTc-DMSA renal scan (planner) and ultrasonography (US) at NINMAS.

Snonographycally approximation of sinus echoes to cortical surface with irregular margins with or without underlying calyceal dilatation and global cortical thinning with decreased length were considered as diffuse scarring. A diffuse or sharp wedge shaped indentation or photopenic area in the contour of the kidney with loss of volume or degree of decreased uptake (either sever or absent) were identified as focal scarring on DMSA scan. In diffuse scarring on DMSA scan defined as differential function of $<45 \%$ with homogenous uptake on the posterior view.

Initially data was analyzed and descriptive statistics such as frequency, percentage, mean, standard deviation (SD) were calculated for the basic demographic characteristics. The comparison findings of DMSA renal scan and US were done by Kappa analysis to see the agreement in the evaluation of size, position, pelvicalyceal dilatation and hydronephrosis of both right and left kidneys. The sensitivity, the specificity, positive predictive value (PPV), negative predictive value (NPV) and accuracy of renal US in the evaluation of focal and diffuse renal scarring, were measured by using the 
statistical formula considering DMSA as gold standard.

\section{RESULTS}

The study population consisted of 85 children with age range of 6 months to 12 years and their mean age was 4.14 years with $\mathrm{SD} \pm 3.21$. Among 85 children 27 were male and 58 were female, indicating that girls were more affected by UTI comparing to the boys (Table 1).

Table 1: Mean (x) age with SD of the study population $(\mathbf{n}=\mathbf{8 5})$.

\begin{tabular}{|l|c|c|c|c|}
\hline Sex & $\begin{array}{c}\text { Number of } \\
\text { Cases(n) }\end{array}$ & Percentage & $\begin{array}{c}\text { Mean (x) } \\
\text { Age (years) }\end{array}$ & SD \\
\hline Male & 27 & 31.8 & 4.23 & \pm 3.09 \\
\hline Female & 58 & 68.2 & 4.10 & \pm 3.28 \\
\hline Total & 85 & 100 & 4.14 & \pm 3.21 \\
\hline
\end{tabular}

Among 85 children, 26 (30.6\%) had normal DMSA scan findings and 59 (69.4\%) had abnormal DMSA scan findings (Table 2).

Table 2: Distribution of the study population according to different age range.

\begin{tabular}{|c|c|c|c|}
\hline Age group & $\begin{array}{c}\text { Total number } \\
\text { (percentage) }\end{array}$ & $\begin{array}{c}\text { Male } \\
\text { (percentage) }\end{array}$ & $\begin{array}{c}\text { Female } \\
\text { (percentage) }\end{array}$ \\
\hline 6 month to $<2$ years & $26(30.5)$ & $9(34.6)$ & $17(65.3)$ \\
\hline 2 years to $<6$ years & $31(36.47)$ & $8(25.8)$ & $23(74.1)$ \\
\hline 6 years to 12 years & $28(32.9)$ & $10(35.7)$ & $18(64.2)$ \\
\hline Total & $85(100.00)$ & $27(31.6)$ & $58(68.23)$ \\
\hline
\end{tabular}

In case of US, 23 (27.1\%) had normal US findings and $62(72.9 \%)$ had abnormal US findings of renal system (Table 3$)$.

Table 3: Kappa Agreement statistical analysis between DMSA renal scan and US for the evaluation of size of right and left kidney $(n=85)$.

\begin{tabular}{|c|c|c|c|c|c|c|c|}
\hline \multirow[t]{2}{*}{ DMSA scan } & \multicolumn{4}{|c|}{ US } & & \multirow{2}{*}{$\begin{array}{c}\text { Kappa } \\
\text { value }\end{array}$} & \multirow{2}{*}{$\begin{array}{c}\mathbf{P} \\
\text { Value }\end{array}$} \\
\hline & Big & Small & Normal & Not visualized & Total & & \\
\hline \multicolumn{8}{|l|}{ Right kidney } \\
\hline Big & 13 & 0 & 10 & 0 & 23 & \multirow{4}{*}{0.349} & \multirow{4}{*}{$0.001^{\mathrm{s}}$} \\
\hline Small & 0 & 2 & 5 & 2 & 9 & & \\
\hline Normal & 12 & 0 & 38 & 1 & 51 & & \\
\hline Not visualized & 0 & 0 & 0 & 2 & 2 & & \\
\hline Total & 25 & 2 & 53 & 5 & 85 & & \\
\hline \multicolumn{8}{|l|}{ Left kidney } \\
\hline Big & 20 & 3 & 8 & 0 & 31 & \multirow{4}{*}{0.490} & \multirow{4}{*}{$0.001^{\mathrm{s}}$} \\
\hline Small & 0 & 3 & 3 & 0 & 6 & & \\
\hline Normal & 8 & 0 & 36 & 0 & 44 & & \\
\hline Not visualized & 1 & 1 & 1 & 1 & 4 & & \\
\hline Total & 29 & 7 & 48 & 1 & 85 & & \\
\hline
\end{tabular}

The ureter and the urinary bladder of each child were assessed by US. Among 62 children having abnormal US findings, $14(22.58 \%)$ cases had dilated ureters on both sides, $3(4.83 \%)$ had rightsided dilated ureter, $7(11.29 \%)$ had left sided dilated ureter on US (Table 4).

Table 4: Kappa Agreement statistical analysis between DMSA renal scan and US for the evaluation of position of right and left kidney $(n=85)$

\begin{tabular}{lccccc}
\hline \multirow{2}{*}{ DMSA scan } & \multicolumn{2}{c}{ US } & & $\begin{array}{c}\text { Kappa } \\
\text { Value }\end{array}$ & $\begin{array}{c}\text { P } \\
\text { Value }\end{array}$ \\
\cline { 2 - 3 } & Normal & Abnormal & Total & & \\
\hline Right kidney & 79 & 0 & 79 & 0.903 & $0.001^{\mathrm{s}}$ \\
Normal & 1 & 5 & 6 & & \\
Abnormal & 80 & 5 & 85 & & $0.001^{\mathrm{s}}$ \\
\hline Total & 75 & 4 & 79 & 0.417 & \\
\hline Left kidney & 3 & 3 & 6 & & \\
Normal & 78 & 7 & 85 & & \\
Abnormal & & & & & \\
\hline Total & 78 & & & & \\
\hline
\end{tabular}

Among 62 children having abnormal US findings, $11(17.74 \%)$ had thickened urinary bladder wall and $11(17.74 \%)$ had thickened and irregular urinary bladder wall (Table 5).

Table 5: Kappa Agreement statistical analysis between DMSA renal scan and US for the evaluation of pelvicalyceal dilatation of right and left kidney ( $n=$ 85).

\begin{tabular}{|c|c|c|c|c|c|}
\hline \multirow{2}{*}{ DMSA scan } & \multicolumn{2}{|c|}{ US } & \multirow[b]{2}{*}{ Total } & \multirow[t]{2}{*}{ Kappa value } & \multirow{2}{*}{$\begin{array}{c}P \\
\text { Value }\end{array}$} \\
\hline & Present & Absent & & & \\
\hline \multicolumn{6}{|l|}{ Right kidney } \\
\hline Present & 5 & 0 & 5 & \multirow{2}{*}{0.157} & \multirow{2}{*}{$0.007^{\mathrm{s}}$} \\
\hline Absent & 31 & 49 & 80 & & \\
\hline Total & 36 & 49 & 85 & & \\
\hline \multicolumn{6}{|l|}{ Left kidney } \\
\hline Present & 7 & 0 & 7 & \multirow{2}{*}{0.141} & \multirow{2}{*}{$0.011^{\mathrm{s}}$} \\
\hline Absent & 39 & 39 & 78 & & \\
\hline Total & 46 & 39 & 85 & & \\
\hline
\end{tabular}

The comparisons of DMSA renal scan and US findings were done by Kappa analysis to see the agreement in the evaluation of renal size, position, presence of pelvicalyceal dilatation and hydronephrosis for each kidney. This study gave an impression that DMSA scan and US has good agreement in the evaluation of renal size, position (Table $3 \& 4$ ) and fair agreement in the evaluation of hydronephrosis (Table 6). But in case of mild pelvicaliceal dilatation and other pathology of lower urinary tract and urinary bladder, DMSA and US has slight agreement (Table 5). 
Table 6: Kappa Agreement statistical analysis between DMSA renal scan and US for the evaluation of hydronephrosis of right and left kidney $(n=85)$.

\begin{tabular}{lccccc}
\hline \multirow{2}{*}{ DMSA scan } & \multicolumn{2}{c}{ US } & & $\begin{array}{c}\text { Kappa } \\
\text { Value }\end{array}$ & $\begin{array}{c}\text { P } \\
\text { Value }\end{array}$ \\
\cline { 2 - 3 } & Present & Absent & Total & & \\
\hline Right kidney & 6 & 2 & 8 & 0.231 & $0.006^{\mathrm{s}}$ \\
Normal & 6 & 56 & 77 & & \\
Abnormal & 21 & 58 & 85 & & \\
\hline Total & 27 & 58 & & & $0.001^{\mathrm{s}}$ \\
\hline Left kidney & 10 & 3 & 13 & 0.336 & \\
$\quad$ Normal & 19 & 53 & 72 & & \\
Abnormal & 29 & 56 & 85 & & \\
\hline Total & & & & & \\
\hline
\end{tabular}

Table 7: Comparison between renal US and DMSA scan for the evaluation of focal scarring of right $\&$ left kidney $(n=85)$.

\begin{tabular}{|c|c|c|}
\hline \multirow[t]{2}{*}{ US } & \multicolumn{2}{|c|}{ DMSA } \\
\hline & $\begin{array}{l}\text { Positive } \\
(\mathrm{n}=10)\end{array}$ & $\begin{array}{l}\text { Negative } \\
(\mathrm{n}=75)\end{array}$ \\
\hline \multicolumn{3}{|l|}{ Right kidney } \\
\hline Positive $(n=3)$ & $\begin{array}{c}2 \\
\text { (True positive) }\end{array}$ & $\begin{array}{c}1 \\
\text { (False positive) }\end{array}$ \\
\hline Negative $(n=82)$ & $\begin{array}{c}8 \\
\text { (False negative) }\end{array}$ & $\begin{array}{c}74 \\
\text { (True negative) }\end{array}$ \\
\hline Left kidney & $\begin{array}{l}\text { Positive } \\
(\mathrm{n}=19)\end{array}$ & $\begin{array}{c}\text { Negative } \\
(\mathrm{n}=66)\end{array}$ \\
\hline Positive (n=7) & $\begin{array}{c}4 \\
\text { (True positive) }\end{array}$ & $\begin{array}{c}3 \\
\text { (False positive) }\end{array}$ \\
\hline Negative $(n=78)$ & $\begin{array}{c}15 \\
\text { (False negative) }\end{array}$ & $\begin{array}{c}63 \\
\text { (True negative) }\end{array}$ \\
\hline
\end{tabular}

Table 8: Comparison between renal US and DMSA scan for the evaluation of diffuse scarring of right $\&$ left kidney $(n=85)$.

\begin{tabular}{|c|c|c|}
\hline \multirow[t]{2}{*}{ US } & \multicolumn{2}{|c|}{ DMSA } \\
\hline & $\begin{array}{c}\text { Positive } \\
(\mathrm{n}=6)\end{array}$ & $\begin{array}{c}\text { Negative } \\
(n=79)\end{array}$ \\
\hline \multicolumn{3}{|l|}{ Right kidney } \\
\hline Positive $(n=0)$ & 0 & 0 \\
\hline Negative (n=85) & 6 & 79 \\
\hline & (False negative) & (True negative) \\
\hline Left kidney & $\begin{array}{c}\text { Positive } \\
(n=4)\end{array}$ & $\begin{array}{c}\text { Negative } \\
(\mathrm{n}=81)\end{array}$ \\
\hline Positive ( $n=2$ ) & $\begin{array}{c}2 \\
\text { (True positive) }\end{array}$ & $\begin{array}{c}0 \\
\text { (False positive) }\end{array}$ \\
\hline Negative (n=83) & $\begin{array}{c}2 \\
\text { (False negative) }\end{array}$ & $\begin{array}{c}81 \\
\text { (True negative) }\end{array}$ \\
\hline
\end{tabular}

The sensitivity, the specificity, positive predictive value (PPV), negative predictive value (NPV) of the US were calculated for the evaluation of focal and diffuse scarring for both kidneys. DMSA scan was used as the gold standard. US were considered a "true positive" if the evaluation of the renal scarring exactly matched the defect reported on DMSA scan. In this study, for the evaluation of focal scarring of right kidney and left kidney, the sensitivity, the specificity, positive predictive value, negative predictive value were $20.0 \%, 98.7 \%, 66.7 \%, 90.2 \%$ and $21.1 \%, 95.5 \%, 57.1 \%, 80.8 \%$ respectively. The overall accuracy of US for the evaluation of focal scarring of right and left kidney were $89.4 \%$ and $78.8 \%$ respectively (Table-7). For the evaluation of diffuse scarring of right kidney, the sensitivity, the specificity, negative predictive value were $0.0 \%$, $100.0 \%, 92.9 \%$ respectively and for the left kidney, the sensitivity, the specificity, positive predictive value, negative predictive value were $50.0 \%$, $100.0 \%, 100.0 \%, 97.6 \%$ respectively. The overall accuracy of US for the evaluation of diffuse scarring of right and left kidney were $92.9 \%$ and $97.6 \%$ respectively (Table-8).

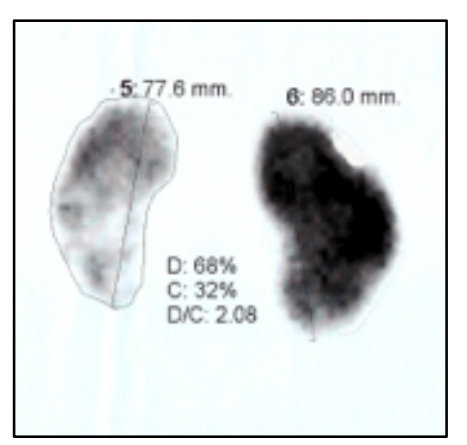

Figure 1. ${ }^{99 \mathrm{~m}}$ Tc-DMSA scan shows kidney size, Split function and scarring.

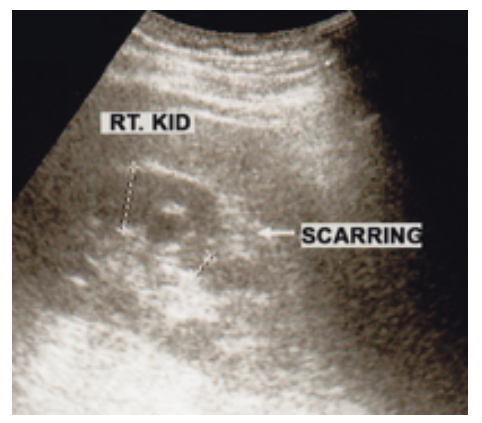

Figure 2. ${ }^{99 m}$ Tc-DMSA scan shows cortical measurement and scarring.

\section{DISCUSSION}

UTI is a common cause of acute illness in children and in some cases it is associated with abnormalities of urinary tract either acquired or congenital (5). In 
recurrent UTI children may develop long-term complications like renal parenchymal scarring, hypertension, chronic impaired renal function and end stage renal failure, if not treated adequately. But UTI in children recovered with an excellent prognosis if it is diagnosed timely and treated adequately $(7,9)$. So that timely diagnosis of underlying abnormalities or pathologies of urinary tract and adequate treatment is necessary.

The risk of UTI varies between different sex and age groups of the children. In childhood, the risk of UTI is $8 \%$ for girls and $2 \%$ for boys (10). In this study, 85 children with recurrent UTI were included by following the inclusion criteria. Among them $58(68.2 \%)$ were girls and $27(31.8 \%)$ were boys, indicating girls were affected more comparing to the boys (Table 1). However during the first year of life, boys are more affected by UTI than girls. The risk increased by tenfold for uncircumcised boys compared to circumcised boys. After infancy the risk of UTI in boys drops to $0.1-0.2 \%$ under age of 5 years and to $0.04-0.2 \%$ in school age boys (11). In this study we noted a reverse risk of UTI in boys during infancy than the girls. We found that, among 18 patients under the age group of 6 months to less than 1year, only 2 were boys and 16 were girls (Table 2). This reverse risk might be due to small size of study population or might be due to early circumcision of the boys, which is practiced in Bangladesh.

There are no established local guidelines in Bangladesh for imaging studies to be performed in the children with UTI. Traditionally DMSA scan, US are used routinely. These two options are also used in many countries.

In pediatric patient with recurrent UTI, it is very important to evaluate the size of the kidney. Most common sequelae of pediatric UTI are pyelonephritis, hydronephrosis and scarring, which frequently affects the kidney size (8). Similarly, some congenital renal abnormalities of kidney size such as small kidney, hypoplastic kidney are sometimes associated with UTI (5). The size of the kidney can be evaluated by DMSA scan and US. In this study, both DMSA renal scan and US were used for the evaluation of size of kidneys. The Kappa agreement statistical analysis between renal US and

DMSA scan was done for the evaluation of size of right and left kidney, which showed good agreement (Table 3). From this good agreement it can be said that either DMSA scan or US is sufficient for measuring the renal size and they are interchangeable. A study reported that in case of size measurement, there was no significant difference between DMSA renal scan and US, which correlates with the present study (12).

Both DMSA scan and US were reported as reliable imaging techniques for evaluating the position of kidney. Khan et al. (13) had stated in his report that all the patients with non-visualized kidney, must be evaluated with US and DMSA renal scan for possible ectopic kidney and agenesis. In this study the Kappa statistical agreement analysis between renal DMSA and US scan for the evaluation of position of right and left kidney showed good agreement. That indicates either DMSA or US is sufficient for position evaluation (Table 4). The congenital abnormalities affecting renal tract like ectopic kidney, horseshoe kidney, crossed renal ectopia or crossed fused ectopia, ptosis can be clearly identified by DMSA renal scanned also provides functional status of the kidney. Along with perfect localization, renal scan plays a vital role in a comprehensive and optimal management strategy of the patients having abnormal positioned kidney. For complete evaluation US and DMSA must be done in combination (14).

Along with malformations, obstruction of the urinary tract is also a predisposing factor for UTI and UTI in children itself is a marker of possible urinary tract obstruction. Hence, evaluation of presence of pelcicalyceal dilatation is important. In this study US identified total 36 kidneys on left side had pelvicalyceal dilatation, out of which, DMSA scan had identified only 5(13.9\%) kidneys. In case of right kidney, US identified 46 kidneys had pelvicalyceal dilatation, out of which, DMSA scan evaluated $7(15.2 \%)$ kidneys had findings of 
pelvicalyceal dilation. Here Kappa agreement statistical analysis between renal US and DMSA scan for the right and left kidney showed slight agreement (Table V). Pelvicalyceal dilatation was detected more by US than DMSA scan. Study reported that ultrasound is more reliable for determining mild renal obstruction, as well as it is a simple and non-invasive means $(7,8)$. The mild dilatation in collecting system could not be evident in DMSA, which is a cortical imaging agent, and its minimum excretion (only 25\%) is through the collecting system $(6,13)$.

In case of hydronephrosis, 27 kidneys on left side with hydronephrosis were identified by US, out of which, 6 (22.2\%) kidneys had hydronephrosis on DMSA scan. USG evaluated total 29 kidneys on right side had hydronephrosis, out of which, DMSA scan evaluated $10 \quad(34.5 \%)$ kidneys had hydronephrosis. Kappa agreement statistical analysis between renal US and DMSA scan for the evaluation of hydronephrosis of right and left kidney showed fair agreement (Table 6). US is most reliable for the diagnosis of hydronephrosis (15). DMSA renal scan showed enlarged kidney with nonhomogenous cortical tracer uptake with central or medial photon deficient areas in case of hydronephrosis (6).

The criteria described by Patel et al. (16) were followed in this study for identifying focal and diffuse cortical scaring. According to the criteria, on DMSA renal scan any diffuse or sharp indentation in the contour of the kidney with loss of volume or degree of decreased uptake (either sever or absent) were evaluated as focal scarring. In diffuse scarring, on DMSA scan defined as differential function of $<45 \%$ with homogenous uptake on the posterior view (17). In US studies scarring was defined according to the criteria proposed by Barry et al. (18). This included focal approximation of sinus echoes to cortical surface with or without underlying calyceal dilatation and irregular margins, which were considered as focal scarring. Global cortical thinning with decreased renal length was taken as diffuse scarring on US.

The present study demonstrated that although US has a good specificity in the detection of renal scarring compared to DMSA scan as the gold standard, it has low sensitivity. These findings support the previous studies those worked with large number of study population. $(4,17,18)$ That indicated disagreement between US and DMSA in the detection of renal scarring.

Due to low level of urinary excretion (approximately $25 \%$ of the dose), ureters and lower urinary tract including bladder could not be assessed with $99 \mathrm{mTc}$-DMSA renal scan (6). Ultrasound is a noninvasive test that can demonstrate the presence of dilatation and duplication of ureters, the presence of ureteroceles, non refluxing megaureter or any other bladder pathology which may be associated with UTI in young children (19). In this study, the ureter and the urinary bladder of each child was assessed by US. Abnormalities of ureter and bladder associated with recurrent UTI could be better evaluated by US than DMSA renal scan.

US is a good imaging modality in the evaluation of kidney, ureter and urinary bladder pathology, which is either congenital or acquired. Some renal abnormalities were better evaluated by doing DMSA and US was appropriate for others. For all these reasons the results of these studies are not mutually interchangeable. Both DMSA scan and US are needed to recommend in combination to evaluate renal abnormalities in children with recurrent UTI.

\section{CONCLUSION}

In the evaluation of kidney size, position and presence of hydronephrosis, both DMSA and US can be interchangeable. Whereas DMSA was underestimated compared to US in the evaluation of mild pelvicaliceal dilatation. On the other hand DMSA renal scan is more sensitive and specific for detecting cortical scarring comparing to the US. US 
is a good imaging modality for the evaluation of abnormalities of ureter and urinary bladder. In light of present study, both DMSA scan and US are recommended in the combination for complete

\section{REFERENCES}

1. Goddard J, Turner AN, Cumming AD, Stewart LH. Kidney and Urinary Tract Disease. In: Boon NA, College NR, Walker BR, Hunter JAA, eds. Davidson's Principles \& Practice of Medicine. London, Churchill Living Stone; 2006: 460-467.

2. Ahmed SM, Swedlund SK. Evaluation and Treatment of Urinary Tract Infection in Children. Am Fam Physician 1998:57(1): 1573-1580.

3. Ahmadzadeh A, Askarpour S. Association of Urinary Tract Abnormalities in Children WithFirst Urinary Tract Infection. Pak J Med Sci 1998:23(1): 88-91.

4. Christian MT, McColl JH, Mackenzie JR, Beattie TJ. Risk assessment of renal cortical scarring with urinary tract infection by clinical features and ultrasonography. Arch Dis Child 2000:82:376-380.

5. Muttarak M, Sriburi T. Congenital renal anomalies detected in adulthood. Biomed Imaging Interv J 2011:8(1):1-8.

6. Ziessman HA, O'Malley JP, Thrall JH. Nuclear Medicine: the requisite in radiology. Philadelphia, WH Saunders;2006:215-262.

7. Luk WH, Woo YH, Au-Yueng AW, Chan JCS. Imaging in Pediatric Urinary Tract Infection: A 9-Year Local Experience.AJR 2009:192:12531260.

8. Al-naddawi MN, Rida MF. Radiological findings in pediatric patients with urinary tract infection.J Fac Med Baghdad 2011:53(3):257-258.

9. Panaretto KS, Craig JC, Knight JC, HowmanGiles R, Shrushkumar P, Roy LP. Risk factor for recurrent urinary tract infection in preschool children. J. Paediatr. Child Health 1999:35: 454459.

10. White B. Diagnosis and Treatment of Urinary Tract Infection in Children. American Family Physician 2011:83(4):409-415. evaluation of renal abnormalities in children with recurrent UTI.

11. Foxman B. Epidemiology of Urinary Tract Infections: Incidence, Morbidity and Economic Status. Dis Mon 2003:49:53-70.

12. Kim BW, Song MK, Chung S, Kim KS. Evaluation of kidney Size in Children: a pilot study of renal length as a surrogate of organ growth. Korean J Pediatric 2012:55(2):54-57.

13. Khan SH, Rather TA, Khan MA. Tc-99m DTPA Scintigraphy and Renal Ectopia: A Retrospective Analysis. Indian Journal of Nuclear Medicine 2005:20(1):9-13.

14. Maisey $\mathrm{MN}$, Britton KE, Collier $\mathrm{BD}$, eds. Clinical Nuclear Medicine. London, Chapman \& Hall;1998:412-416.

15. Morin ME, Baker DA. The Influence of hydration and bladder distension on the sonographic diagnosis of hydronephrosis. J Clin Ultrasound 1979:7:190-194.

16. Patel K, Charron M, Hoberman A, Brown ML, Roger KD. Intra- and Interobserver Variability in Interpretation of DMSA scans using a set of Standardized Criteria. Pediatric Radiology 1983:23:506-509.

17. Moorthy I, Wheat D, Gordon I. Ultrasonography in the evaluation of renal scarring using DMSA scan as the gold standard. PediatricNephrol 2004:19:153-156.

18. Barry BP, Hall N, Cornford E, Broderick NJ, Somes JM, Rose DH. Improved ultrasound detection of renal scarring in children following urinary tract infection. Clinical Radiology 1998:53:747-751.

19. Hoberman A, Charron M, Hickey RW, Baskin M, Kearney, DH, Wald ER. Imaging Studies after a First Urinary Tract Infection in Young Children. N Eng J Med 2003:348:195-201. 